\title{
IMPLEMENTAÇÃO DE CURSOS LIVRES E ABERTOS (MOOCS) NA UNIVERSIDADE ESTADUAL DO MARANHÃO
}

\author{
SÃO LUÍS/MA JULHO/2018 \\ Kátia Almeida Fonsêca - UEMA - katiafonseca.uemanet@gmail.com \\ Amilson Pimentel Batalha - CEUMA - a.milson@hotmail.com \\ Suely de Oliveira Falcão - UEMA - sfalcao33@gmail.com \\ Paulo Henrique dos Santos Correa - UEMA - phdesigner.uemanet@gmail.com \\ Tipo: Relato de Experiência Inovadora (EI) \\ Categoria: Métodos e Tecnologias \\ Setor Educacional: EDUCAÇÃO MÉDIA E TECNOLÓGICA
}

\begin{abstract}
RESUMO
A Universidade Estadual do Maranhão oferece desde 2013 Cursos livres e abertos online, mais conhecidos como MOOCs, do inglês Massive Open Online Course, em diferentes áreas, como Educação, Engenharia, Psicologia, Turismo, Administração, dentre outros. Os cursos por ela oferecidos representam o elo entre a Universidade e a sociedade, uma vez que viabilizam a socialização do conhecimento produzido na Universidade. O presente relato tem por objetivo apresentar como é desenvolvido o projeto para a oferta destes cursos e seu consequente crescimento. O estudo consiste numa metodologia de cunho descritivo e bibliográfico, desenvolvido a partir de artigos científicos sobre o tema estudado, fornecendo assim um panorama e evidenciando novas ideias a respeito dos MOOCs. Este trabalho demonstra que a aposta na oferta de cursos dessa natureza tem gerado positivos resultados no sentido de cumprir com a missão democrática de ensino pela Universidade, embora possam ainda apresentar aspectos pedagógicos que ainda necessitem serem estruturados de forma melhor, pontos estes a serem considerados nos próximos estudos.
\end{abstract}

Palavras-chave: Palavras-chave: Educação a Distância. Cursos Livres. MOOCs. 


\section{INTRODUÇÃO}

O inicio do século XXI vem sendo cada vez mais marcado pela diversificada difusão e investimento das tecnologias da informação e da comunicação (TICs) no campo educacional. Isto tem impulsionado uma gama de instituições de ensino superior a explorarem as possibilidades da educação na modalidade a distância. Os ambientes virtuais de ensino-aprendizagem tornam-se aos poucos os grandes responsáveis pelo novo paradigma da forma de compartilhar ensino e conhecimento. Essa vertente, como observam Nova e Alves (2003), consiste no presente potencial transformador que implica em novas formas de aprendizagem e construção de saberes. Nesse âmbito, renovadas instituições de ensino superior vem aderindo prontamente aos chamados MOOCs (Cursos Online Abertos Massivos), dirigidos a um público amplo e de forma gratuita, onde qualquer pessoa com acesso à internet e em qualquer lugar do mundo tenha acesso à plataforma.

Conhecidos no Brasil como Cursos Livres, a Universidade Estadual do Maranhão-UEMA é a primeira Instituição do estado que iniciou com a oferta de cursos livres e abertos. Atualmente conta com um portfólio de 24 cursos online e gratuitos, reunindo diversificadas áreas do conhecimento, associando um processo que engloba flexibilidade para os horários de estudo e diversificados ganhos de conteúdos.

Apresentar como é desenvolvido o projeto para a oferta destes cursos e seu consequente crescimento é o que torna o objetivo deste relato. A relevância do estudo é justificada pela crescente oferta dos cursos abertos, especialmente no presente século, em que o número de cursos e de inscritos em MOOCs se torna cada vez maior.

O presente relato está estruturado com a descrição de um breve histórico e conceito de MOOCs, na sequência abordando as orientações metodológicas, a sistemática dos cursos na Instituição proponente e por fim as considerações finais referentes à experiência implementada com a oferta de cursos livres e abertos.

\section{MOOCs: Definições e História}

MOOC pode ser definido como um modelo que integra três elementos: a conectividade das redes sociais, o conhecimento de um especialista em determinada área e a coleção de recursos online abertos (MATTAR, AND FIGUEIREDO 2013).

Seu conceito foi utilizado pela primeira vez no ano de 2008, por Dave Cormier, em menção ao curso sobre conectivismo de Siemens e Downes, desenvolvido na 
Universidade de Manitoba e disponibilizado gratuitamente na internet. Por serem abertos e livres se diferem dos cursos tradicionais de $\mathrm{EaD}$, uma vez que permite o alcance de um número ilimitado de participantes e sem pré-requisito de formação.

Os cursos livres se multiplicaram e passa a alcançar cada mais a popularidade com o apoio de diferentes plataformas. Dentre as mais conhecidas estão a Coursera e o edX, sendo estas as mais utilizadas por Universidades Estrangeiras.

No Brasil a primeira a disponibilizar cursos MOOC foi pela Universidade de São Paulo (USP), em 2013. Isso ocorreu através de uma plataforma privada chamada Veduca, também utilizada por outras Universidades Brasileiras. No caso da UEMA os cursos são desenvolvidos por uma Plataforma própria ,onde se utiliza o Moodle para gerenciar criação de diferentes ofertas.De acordo com Izumi (2013), o Brasil é o país que alcança o segundo patamar pelo expressivo número de inscritos em cursos online gratuitos oferecidos por universidades estrangeiras utilizando o site Coursera.

De acordo com Mattos and Bruno (2015), os MOOCS possibilitam o acesso ao conhecimento a partir da proposta de seus autores/gestores ou Instituição, já para Biagiotti (2014), MOOCs são uma ferramenta importante para viabilizar o acesso a conteúdo de qualidade de grandes e renomadas universidades mundiais. Baseado nas afirmações feitas pelos autores, os MOOCs de certa podem servir como uma alavanca na área de tecnologia em temos de criatividade e inovação para a educação a distância, e é neste sentido que a Universidade Estadual caminha para favorecer a democratização do ensino público.

Para Mcauley (et al. 2010), o MOOC é conceituado como um curso online, de inscrição gratuita e aberta, com currículo compartilhado, público e com resultados disponíveis a todos. Cormier (2010) ratifica esse caráter, destacando que por ser aberto, as pessoas podem ter acesso ao conteúdo sem precisar pagar para isso. Somando a isso, Pisutova (2012), atribui a definição de MOOC como um modelo para disponibilização de conteúdos de aprendizagem on-line para qualquer pessoa que queira fazer um curso, onde este possui como principais características ser aberto, gratuito, colaborativo e distribuído. É nesse contexto que a UEMA tem validado a construção e condução dos seus cursos, dispondo dos significativos conteúdos produzidos no meio acadêmico. $O$ certo é que não há consenso quanto à definição e, inclusive, quanto aos propósitos educacionais.

Apesar de serem conceituados como cursos livres e abertos, nem todos possuem essa característica peculiar, ou seja, a grande maioria não são abertos e massivos. Bastos e 
Biagiotti (2014) menciona que existem aqueles que são abertos, mas não massivos ao estabelecerem um limite de participantes, outros são massivos, no entanto não abertos, por requererem uma possível taxa a ser paga pela certificação ou porque estabelecem algum pré- requisito de conhecimento.

Em contrapartida, os cursos dessa natureza avançam, geralmente seguindo um padrão de curta duração, com uma carga horária satisfatória e alguns até com a possibilidade de certificação.

Destarte, o que se pode vê é que dependendo da natureza de cada MOOC, estes estão em constante implementação, conforme corroboram Bottentuit (2015) afirmando que a evolução de seus formatos e funções têm sido crescente pela ação de especialistas em design instrucional e pelos provedores interativos mais populares para fazer um MOOC, com o objetivo de aprimorar a educação aberta. De outro modo, o que se vê é que a evolução dos MOOCs tem sido crescente, e sua forma por hora é indefinida (SMITH, 2012).

Deste modo, os dados conceituais só mostram que os cursos dessa natureza são as novas apostas e surgem neste início de século XXI como um ganho em novos estilos de aprendizagem colaborativa em rede, fundamentados nos princípios dessa nova teoria conectivista.

\section{ASPECTOS METODOLÓGICOS}

O presente trabalho retrata um estudo descritivo e bibliográfico, a partir de consulta em livros e artigos que delimitem a temática. $O$ processo de leitura e análise da produção bibliográfica permite conhecer a visão geral de modo que evidencie novas ideias a respeito do assunto estudado. De acordo com Gil (2008, p.14) "as pesquisas exploratórias têm a capacidade de ajudar na formulação de problemas de pesquisa mais precisos". Realizou-se, para isso, a seleção de trabalhos científicos sobre o assunto nos anais de congressos e simpósios utilizando como palavras-chave "MOOC" e "Massive Open Online Courses". Após leitura e categorização dos artigos foram selecionados apenas 10 (dez) que descrevem aspectos sobre implementação, desafios, oportunidades, problemas, provedores e características dos cursos MOOC, servindo então como base para construção e fundamentação desse relato. 


\section{IMPLEMENTAÇÃO DOS MOOCS NA UEMA}

A UEMA é pioneira no estado quando se fala em oferta de cursos a distância. Não obstante, foi também a primeira a investir em projetos de cursos abertos e livres. $\mathrm{O}$ Núcleo de Tecnologias para Educação da Uema- mais conhecido como Uemanet -é o principal intermediador de cursos na modalidade $\mathrm{EaD}$ e por outras ações educacionais que demandem a utilização de recursos tecnológicos. A Universidade Estadual do Maranhão, através de seu Núcleo de Tecnologias passou a romper os limites dos programas especiais presenciais e atualmente vem avançando quanto ao desenvolvimento de diversos modelos de cursos, dentre eles, o Massive Open Online Course (MOOC). A primeira oferta dessa iniciativa acontecia em junho de 2014, com o curso de Negociação, tendo como objetivo proporcionar ao grande público o acesso a todo um material rico produzido pelos profissionais da universidade.

Esta empreitada não difere da metodologia que é adotada pelos diferentes cursos livres e abertos, ou seja, seguimos a tendência mundial dos MOOCs atuais, dispondo os conteúdos dos cursos aos estudantes em múltiplos objetos de aprendizagem.

O planejamento dos cursos envolve um conjunto de processos que vão desde a análise dos objetos de aprendizagem à disposição dos cursos. A etapa envolve uma equipe multidisciplinar de Designer Pedagógico, Designer de Ambiente Virtual de Aprendizagem, Programador de Ava, Professor Conteudistas da área de cada curso, Designer gráfico e Designer de produção audiovisual. $O$ planejamento e a implementação dos cursos abertos da Universidade estão organizados em etapas, conforme figura abaixo:

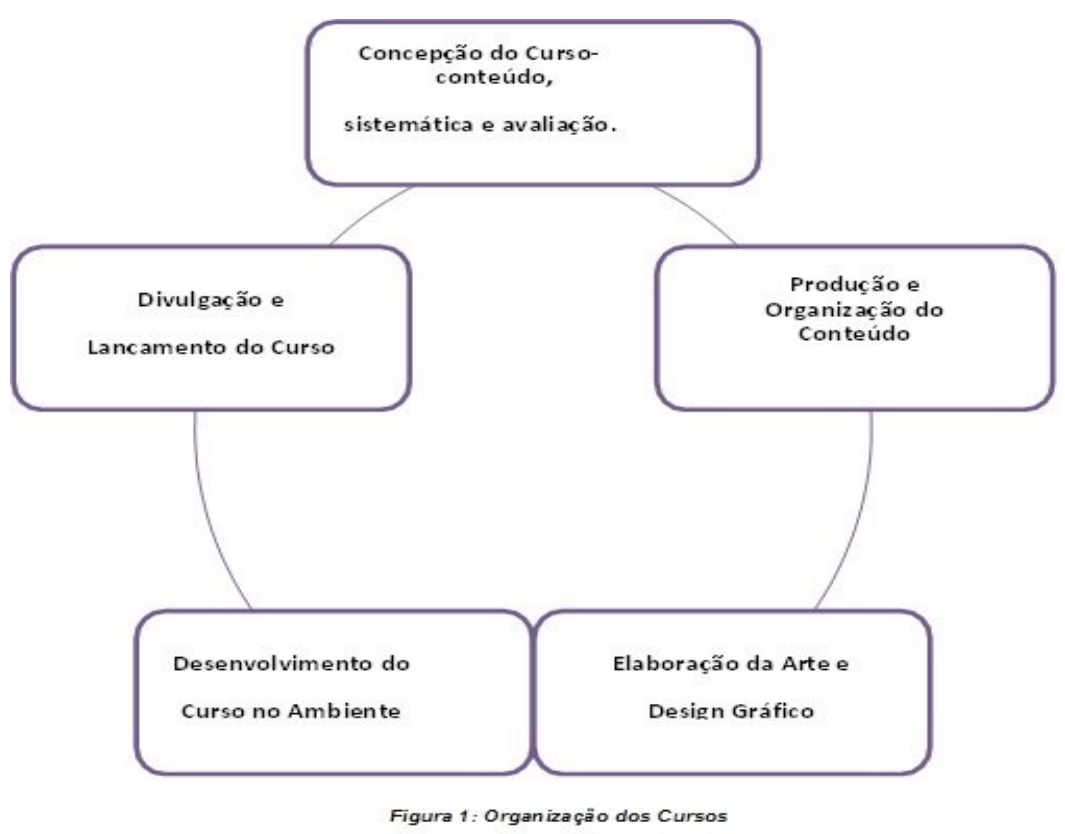


Assim que os cursos são montados e lançados, por meio de um rápido cadastro e da criação de um perfil para acessar o Ambiente Virtual de Aprendizagem (AVA) o participante passa a ter acesso aos cursos, conforme sua conveniência, coaprendendo entre pares por meio da participação nos fóruns e atividades. Com isso Behrens (2005) comenta que:

O processo de mudança paradigmática atinge todas as instituições e em especial a educação e o ensino nos diversos níveis, inclusive e principalmente nas universidades. $\mathrm{O}$ advento dessas mudanças exige da população uma aprendizagem constante. As pessoas precisam estar preparadas para aprender ao longo da vida podendo intervir, adaptar-se e criar novos cenários. (BEHRENS, 2005, p.68).

Atualmente, a Universidade oferta 24 cursos desta natureza, distribuídos nas áreas de Agronomia, Biologia, Direito, Educação, Engenharia, Filosofia, Geografia, Gestão,Turismo e Tecnologia da Informação.São 198.951 participantes inscritos na plataforma, com registro de usuários acessando de 49 Países, tendo a oportunidade de logar as 1.188 atividades gratuitas disponíveis.

\subsection{Sistemática dos Cursos}

A sistemática de organização dos cursos MOOC estão detalhados num plano escrito de trabalho. Neste documento está descrito a identificação e os demais itens que correspondem a natureza do projeto. A esfera responsável pela organização dos cursos é o setor denominado por "Design Educacional". Neste setor existe uma equipe multidisciplinar, composta por: designer pedagógico, designer de vídeo, cinegrafista, editor, videografista, revisor de texto entre outros que darão suporte ao professor-autor, tanto nas questões técnicas, quanto pedagógicas.

Os objetos de aprendizagem são elaborados pelos próprios professores da instituição, onde geralmente são utilizados os conteúdos desenvolvidos para as disciplinas dos cursos de graduação, pós-graduação, tecnólogos e técnicos da universidade. Algumas vezes, apenas como material de apoio e aprofundamento, também são aproveitados os materiais didáticos desenvolvidos pela Universidade Aberta do Brasil (UAB) para os cursos a distância da instituição.

\subsection{Objetos de Aprendizagem e Espaços de Interação}

Os MOOCs da UEMA são compostos por um conjunto específico de objetos de aprendizagem. Entretanto, nem todos os objetos são obrigatórios. É facultativo ao 
professor conteudista determinar quais objetos são imprescindíveis no processo de aprendizagem de conteúdos relativos ao seu curso. Os principais materiais didáticos escolhidos no âmbito dos cursos livres são: o Caderno de Estudos ou E-book de cada disciplina, o Slide com Conteúdo, o Plano de Ensino, o Fórum e Atividade, o Roteiro de Estudo, os Slides de Capacitação dos Tutores e Alunos, as Videoaulas, os Podcats, a escolha do Material Complementar e por fim as Avaliações.

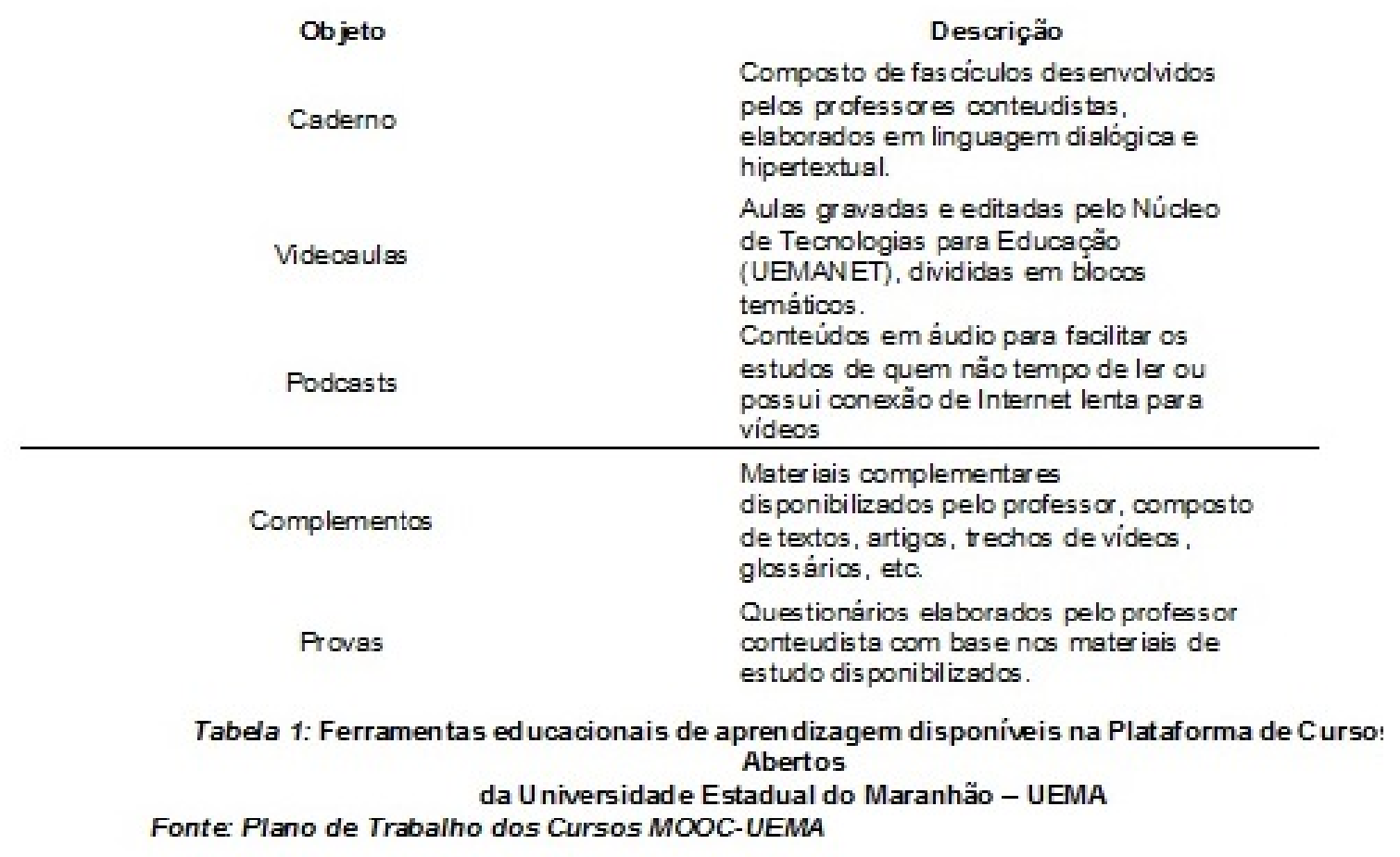

No que tange à estruturação destes cursos, destaca-se que a montagem dos cursos está vinculado à figura de um Professor Conteudistas. Entretanto, os maiores percalços nesse sentido se dá pela não adesão da maioria do corpo docente, uma vez que esta resistência está atrelada ao fato de não haver nenhuma remuneração.

\subsection{Metodologia}

Os conteúdos, a serem estudados de forma livre pelo cursista, estão disponíveis em múltiplas mídias, conforme explicado no item anterior. O participante tem autonomia para conduzir seus estudos de forma não linear, conforme seus próprios interesses.. Os cursistas interagem através de fóruns e também do café virtual, promovendo assim o aprofundamento e construção do conhecimento. Nos "Fóruns" geralmente os estudantes passam a discutir temas propostos pelo professor. Já o "Café Virtual" não possui uma temática especifica, é um ambiente informal de trocas diversas, mas que se 
torna um espaço de convivência e de grande comuta de ideias.Nestes espaços os participantes podem interagir com colaboradores da UEMA, professores e colegas de curso. Este movimento favorece o intercâmbio de informações, experiências e conhecimentos. O objetivo principal é promover a autoaprendizagem mediada pelas tecnologias de informação e comunicação, de forma que os pares sejam sujeitos proativos e conscientes, capazes de aferir sua própria evolução ao longo dos estudos.Ao final de cada curso o estudante tem direito ao certificado. Para isso o estudante precisa obter de $75 \%$ (setenta e cinco por cento) de aproveitamento ao responder a prova, que é um questionário com 08 (oito) questões objetivas.

\section{4 .CONSIDERAÇÕES FINAIS}

Com o registro das informações expressas neste relato, avaliamos que a iniciativa de implantar os primeiros cursos MOOC para além dos muros da universidade, abrindo à comunidade os conteúdos produzidos pelos próprios professores da Instituição e a todos que buscam uma forma de aprender e atualizar seus conhecimentos tem gerado um retorno positivo à Instituição.

Os resultados de acesso e avanço dos cursos abertos vem superando as expectativas, o que pode ser justificado, entre outras razões, pela qualidade dos conteúdos disponibilizados e pela gerência de gratuidade. Atualmente a Universidade oferta 24 cursos dessa natureza, estando presente em 49 Países, com 1188 atividades disponíveis, 198.951 participantes inscritos na plataforma.

Como se vê, o número de usuários inscritos na plataforma demonstra o grande interesse do público por esta oferta de ensino, o que pode ser observado no registro dos 198.951 estudantes participando em cada oferta do curso. Diante desse cenário, a Universidade vem ampliando seu status democrático no sentido de ofertar uma modalidade inovadora de ensino e aprendizagem, amparada pelo uso da internet, conseguindo atender através de sua plataforma própria um número ilimitado de alunos interessados em cursos de curta duração, livre de pré-requisitos e de ritmos impostos por instituições convencionais de ensino.

Destarte, concluímos com este trabalho que as pesquisas não se esgotam e que tanto os registros bibliográficos quanto a experiência implementada por esta Universidade demonstram que os cursos abertos massivos online surgem como oportunidade de acesso aos conhecimentos produzidos no meio acadêmico. Entretanto, há situações que 
necessitam ser revistas como a busca por uma maior adesão do corpo docente da instituição à iniciativa MOOC, bem como o formato da certificação, pontos estes a serem analisados em estudos futuros.

\section{REFFERÊNCIAS}

ALVES, Lynn; NOVA, Cristiane. Educação a distância: uma nova concepção de aprendizado e interatividade. São Paulo: Futura, 2003.

BEHRENS, M. Aparecida. O paradigma emergente e a prática pedagógica.Petrópolis: Vozes, 2005.

BIAGIOTTI. B. 2014. "MOOCs: Uma Alternativa Para a Democratização Do Ensino." Revista RENOTE 12: 1-9.

UMINHO. B.Bottentuit. 2015. "CURSOS ONLINE ABERTOS E MASSIVOS ( MOOCS ): Possibilidades de Formação Continuada a Distância.” no1: 1-19.

CORMIER,D. What is a MOOC? Disponível em: $<$ http://www.yotube.com/watch?v=eW3gMGqcZQc\#!2010> Acesso em: 25 abr. 2018.

CID.R. Bastos; Biagiotti. B. MOOCs: uma alternativa para a democratização do ensino.2014.Disponível em :aprov/127990.pdf>. Acesso em: 20 abr .2018.

GIL, A.Carlos. Métodos e técnicas de pesquisa social. 6 ed. São Paulo: Atlas,2008.

IZUMI, C.E. Brasil é o segundo país em número de inscritos em cursos online de universidades americanas. Disponível em: . Acesso em: 01 abr. 2018.

MCAULEY, A. STEWART,B.CORMIER,D \& SIEMENS, G.(2010).In the Open: TheMOOC model for digital practice. SSHRC Aplication, Knowledge Synthesis for the Digital Economy.

MATTAR,J. Aprendizagem em ambientes virtuais: teorias, conectivismo e MOOCs. Teccogs, n. 7,p. 21-40, jan-jun.2013.Disponível em:<http://goo.gl/2wzSJs>.Acesso em: 30 mar. 2018. 
MATTOS. A.C. G. and Adriana Rocha Bruno. 2015. "Emergências Da Educação Aberta No Contemporâneo: Mooc, Rea E Pomar." 37a Reunião Nacional da ANPEd.

PISUTOVA, K. Open education. In: IEEE INTERNATIONAL CONFERENCE ON EMERGING ELEARNING TECNOLOGIES AND APLICATONS,10.2012,Stará Lesná. Anais...Stará Lesná,IEEE,2012.p.297-300.

SMITH, L. 5 Provedores de educação que oferecem MOOCs agora ou no futuro.Education. Disponível em:://www.educationdive.com/news/5moocproviders/44506/>. Acesso em : 30 mar.2018. 